УДК 519.85:517.977.5:338.27

https://doi.org/10.35546/kntu2078-4481.2021.2.24

Г.О. ДИМОВА

Херсонський державний аграрно-економічний університет ORCID: 0000-0002-5294-1756

О.В. ЛАРЧЕНКО

Херсонський державний аграрно-економічний університет ORCID: 0000-0001-7857-0802

\title{
ВИКОРИСТАННЯ МЕТОДУ ДЕКОМПОЗИЦІЇ ДЛЯ МОДЕЛЮВАННЯ БАГАТОГАЛУЗЕВОЇ ЕКОНОМІЧНОЇ СИСТЕМИ
}

У статті увага приділена питанням побудови динамічної моделі багатогалузевої економічної системи на основі законів збереження (метод динамічних рівнянь Леонтьєва) $i$ методам їхнього рімення.

При розробці економіко-математичного апарату для аналізу, планування $і$ прогнозування багатогалузевого виробництва створюється система моделей, заснована на уявленні виробниитва як складної ісрархічної системи. Верхній рівень системи моделей утворюють макроекономічні системи, які дозволяють виявити зміни вільних показників і дають ияінну інформацію про темпи і пропориії розвитку багатогалузевого виробництва. У моделі міжгалузевого балансу передбачається, щуо кожна галузь виробляє тільки один продукт $і$ кожен продукт виробляється тільки однією галуззю або одним технологічним способом. Але якщчо розглянути виробництво якого-небудь певного виду продукиії, то виявлясться можливість отримання цฺього продукту кількома технологічними способами. Існує безліч різних варіантів виробництва продуктів з метою задоволення кінщевого попиту на ті чи інші види продукиії. Природно, щзо різні варіанти вимагають неоднакових витрат $і$ приносять неоднаковий економічний ефект. Тому виникає проблема оптимізаціі - проблема вибору найкращого, найбільш оптимального варіанту виробництва. Проблема оптимізаиії великих систем виявляється проблемою створення методів розв'язання задач математичного програмування великої розмірності. Для розв'язання таких задач в даній статті використовується метод декомпозиції.

У результаті реалізації метода декомпозииї початкова система розкладається на підсистеми, для кожної з яких необхідно розв'язувати підзадачу мениої розмірності. Ці підсистеми взаємозалежні. Загальне розв 'язання не можна отримати в результаті ізольованого розв'язку таких підзадач. В роботі побудована модель багатогалузевої економічної системи та алгоритму знаходження оптимальних параметрів та виявлено, щчо при умові, щчо координуюча задача є невиродженою, на кожній ітерації значення иільової функиії зменшується. При існуванні тільки кінцевого числа можливих базисів $і$ при умові, щзо не один з базисів не використовується двічі, використання методу декомпозицї приводить до оптимального рішення за кінцеве число ітерацій.

Ключові слова: модель «витрати-випуск», велика розмірність, багатогалузева економічна система, декомпозиція, лінійне програмування, характеристичні різниці.

А.О. ДЫМОВА

Херсонский государственный аграрно-экономический университет ORCID: 0000-0002-5294-1756

О.В. ЛАРЧЕНКО

Херсонский государственный аграрно-экономический университет ORCID: 0000-0001-7857-0802

\section{ИСПОЛЬЗОВАНИЕ МЕТОДА ДЕКОМПОЗИЦИИ ДЛЯ МОДЕЛИРОВАНИЯ МНОГООТРАСЛЕВОЙ ЭКОНОМИЧЕСКОЙ СИСТЕМЫ}

В статье внимание уделено вопросам построения динамической модели многоотраслевой экономической системы на основе законов сохранения (метод динамических уравнений Леонтьева) $и$ методам их решения.

При разработке экономико-математического аппарата для анализа, планирования $u$ прогнозирования многоотраслевого производства создается система моделей, основанная на представлении производства как сложной иерархической системы. Верхний уровень системы моделей образуют макроэкономические системы, которые позволяют выявить изменения свободных показателей и дают иенную информацию о темпах и пропоричия развития многоотраслевого производства. В модели межотраслевого баланса предполагается, что каждая отрасль производит только один продукт и каждый продукт производится только одной отраслью или одним технологическим способом. Но если рассмотреть производство какого-либо определенного вида 
продукции, то выявляется возможность получения этого продукта несколькими технологическими способами. Существует множество различных вариантов производства продуктов с иелью удовлетворения конечного спроса на те или иные виды продукции. Естественно, что различные варианты требуют неодинаковых затрат и приносят неодинаковый экономический эффект. Поэтому возникает проблема оптимизации - проблема выбора наилучшего, наиболее оптимального варианта производства. Проблема оптимизаиии больших систем выявляется проблемой создания методов решения задач математического программирования большой размерности. Для решения таких задач 6 данной статье используется метод декомпозиции.

В результате реализации метода декомпозиции начальная система разлагается на подсистемы, для каждой из которых необходимо решать подзадачу меньшей размерности. Эти подсистемы взаимосвязаны. Общее решение нельзя получить в результате изолированного решения таких подзадач. В работе построена модель многоотраслевой экономической системы и алгоритма нахождения оптимальных параметров и обнаружено, что при условии, что координирующая задача является невырожденной, на каждой итерации значение целевой функции уменьшается. При сущзествовании только конечного числа возможных базисов и при условии, что не один из базисов не используется дважды, использование метода декомпозииии приводит к оптимальному решению за конечное число итераций.

Ключевые слова: модель «затрать-выпуск», большая размерность, многоотраслевая экономическая система, декомпозиция, линейное программирование, характеристические разности.

\author{
H. DYMOVA \\ Kherson State Agrarian and Economic University \\ ORCID: 0000-0002-5294-1756 \\ O. LARCHENKO \\ Kherson State Agrarian and Economic University \\ ORCID: 0000-0001-7857-0802
}

\title{
USING THE DECOMPOSITION METHOD TO SIMULATE A DIVERSIFIED ECONOMIC SYSTEM
}

The article focuses on the issues of constructing a dynamic model of a diversified economic system based on conservation laws (the method of dynamic Leontief equations) and methods for their solution.

When developing an economic and mathematical apparatus for the analysis, planning and forecasting of diversified production, a system of models is created based on the representation of production as a complex hierarchical system. The upper level of the system of models is formed by macroeconomic systems that make it possible to identify changes in free indicators and provide valuable information about the rates and proportions of development of diversified production. The model of interbranch balance assumes that each industry produces only one product and each product is produced by only one industry or one technological method. But if consider the production of any particular type of product, then the possibility of obtaining this product in several technological ways is revealed. There are many different options for the production of products in order to meet the final demand for certain types of products. Naturally, different options require unequal costs and bring unequal economic effect. Therefore, an optimization problem arises - the problem of choosing the best, most optimal production option. The problem of optimizing large systems is revealed by the problem of creating methods for solving problems of mathematical programming of large dimensions. To solve such problems, this article uses the decomposition method.

As a result of the implementation of the decomposition method, the initial system is decomposed into subsystems, for each of which it is necessary to solve a subproblem of a lower dimension. These subsystems are interconnected. A general solution cannot be obtained by isolation solving such subproblems. The paper builds a model of a multi-sectoral economic system and an algorithm for finding the optimal parameters, and it is found that, provided that the coordinating task is non-degenerate, the value of the objective function decreases at each iteration. If there are only a finite number of possible bases and provided that none of the bases is used twice, the use of the decomposition method leads to an optimal solution in a finite number of iterations.

Keywords: model "input-output", large dimension, diversified economic system, decomposition, linear programming, characteristic differences.

\section{Постановка проблеми}

Моделі функціонування й оптимізації економічних об’єктів, як правило характеризуються наступними особливостями [1]:

- функціональні зв'язки між параметрами системи описуються набором великого числа рівнянь $\mathrm{i}$ нерівностей $з$ відносно великим числом змінних; 
- в структурі функціональних зв'язків є специфіка, що вказує на можливість більш-менш повного розчленування системи рівнянь і нерівностей на підсистеми меншої розмірності.

При такому трактуванні проблеми теорії оптимізації великих систем виявляються проблемою створення методів розв'язання задач математичного програмування великої розмірності, що використовують специфіку структури зв'язків і криторіальної функції.

\section{Аналіз останніх досліджень і публікацій}

Останнім часом розв'язання задач великої розмірності грунтується на ідеях декомпозиції (розкладання), у результаті реалізації яких початкова система розкладається на підсистеми, для кожної 3 яких необхідно розв'язувати підзадачу меншої розмірності [2]. Оскільки підсистеми взаємозалежні (через цільову функцію), то загальне розв'язання не можна отримати в результаті ізольованого розв'язку таких підзадач. Виділяються підсистеми першого і другого рівня. Підсистеми другого рівня визначають відповідні зміни першого рівня, при цьому як перші, так і другі можуть бути нелінійними. Глибина ієрархій може бути більше ніж два, тоді підсистеми третього рівня визначають зміни другого рівня і т.д. координуючий орган впливає на розв'язок підзадач шляхом зміни значень коефіцієнтів цільової функції (у випадку дворівневих задач), уведенням додаткових обмежень і т.д.

Головний недолік цього методу складається в необхідності багаторазового повернення до розв'язання окремих підзадач.

При проектуванні (створенні моделі) макроекономічної системи насамперед виділяються основні технологічні способи, кожний з таких способів можна розглядати у виді «чорної скриньки» із вхідними і вихідними потоками витрат (різні види праці, сировини, матеріалів та інше). Модель «витрати-випуск», уперше запропонована В.В. Леонтьєвим, знайшла широке застосування в описі макроекономічних систем [3]. Найпростіший варіант цієї моделі включає $n$ технологічних способів, що відповідає окремим галузям або групам галузей. Передбачається, що способи задовольняють умовам пропорційності, незаперечності та адитивності. При використанні технологічних способів виробляється тільки один продукт, що може споживатися усередині системи або виступати як кінцевий продукт, попит на який у формі індивідуального або суспільного споживання, а також експорту, передбачається заданим.

\section{Формулювання мети дослідження}

Метою роботи $\epsilon$ створення методів розв'язання задач математичного програмування великої розмірності та побудова моделі багатогалузевої економічної системи й алгоритму знаходження оптимальних параметрів методом декомпозиції.

\section{Викладення основного матеріалу дослідження}

Нехай $x_{i}$ - інтенсивність використання I-го технологічного способу - загальний (валовий) випуск продукції $i$-ї галузі; $d_{i}-$ попит (кінцевий продукт) на продукцію $i$-ї галузі; $a_{i}-$ кількість продукції $i$-ї галузі, що необхідна для виробництва одиниці продукції $j$-і галузі (відома технологічна матриця А) [2]

$$
x_{i}-\sum_{j=1}^{n} a x_{j}=d_{i}
$$

або в матричній формі

$$
(\mathbf{I}-\mathbf{A}) x=d .
$$

Система (2) має або єдине ненегативне рішення або такого рішення не існує. Для динамічної моделі крім цього задається матриця капітальних витрат $\mathbf{B}$, елементи якої $b_{i j}$ позначають витрати продукції $i$-ї галузі на збільшення випуску на одну одиницю в $j$-й галузі. Елементи матриць $\mathbf{A}$ i $\mathbf{B}$ під зовнішнім впливом змінюються в часі. Нехай $d_{t}$ - кінцевий попит на продукцію в $t$-м періоді, $c_{t}-$ виробнича потужність наприкінці періоду $t$ (вимірюється в одиницях випуску продукції); $x_{t}$ - випуск продукції в періоді $t ; n_{t}-$ збільшення (приріст) потужності в періоді $t ; s_{t}$ - рівень запасу продукції наприкінці $t$-го періоду; $u_{t}$ - недовикористана виробнича потужність протягом періоду $t$. Тоді основне балансове рівняння для динамічної моделі «витрата-випуск» прийме вид

$$
\begin{gathered}
x_{t}=\mathbf{A} x_{t}+d_{t}+\mathbf{B} n_{t}+s_{t}-s_{t-1}, \quad t=1,2, \ldots, T \\
c_{t}=c_{t-1}+n_{t}
\end{gathered}
$$

або 


$$
c_{t}=c_{0}+\sum_{\tau=1}^{t} n_{\tau} .
$$

Випуск продукції в періоді $t$ обмежений існуючою потужністю, так що $x_{t} \leq c_{t}$ або

$$
\begin{gathered}
x_{t}+u_{t}=c_{t}, \\
d_{t}, c_{t}, x_{t}, n_{t}, s_{t}, u_{t} \geq 0 .
\end{gathered}
$$

Передбачається, що відомі $c_{0}$ - початкова потужність, $s_{0}$ - початковий запас; $d_{1}, d_{2}, \ldots, d_{T}-$ кінцевий попит для всіх періодів. Використовуючи рівняння (5) для виключення змінних $c_{t}$, задача зводиться до блочно-діагональної структури, що має велику кількість стовпців. При розв'язанні таких задач виникає питання про існування припустимого рішення системи (3)-(6). Відповідь на нього позитивний, якщо початковий запас такий, що за рахунок його може бути задоволений попит для всіх періодів. Тоді не виникає необхідності в збільшенні потужності та утворення нових запасів, і тому, припустивши $n_{t}=s_{t}=0, t=1, \ldots, \mathrm{T}$ у рівнянні (3), отримаємо

$$
\begin{gathered}
x_{1}=(\mathbf{I}-\mathbf{A})^{-1}\left(d_{1}-s_{0}\right) \\
x_{t}=(\mathbf{I}-\mathbf{A})^{-1} d_{t}, \quad t=2, \ldots, T
\end{gathered}
$$

Ці значення $x_{1}$ та $x_{t}(t=2, \ldots, T) \in$ допустимими, якщо значеннями змінної $u_{t}$ у рівнянні (6) $\epsilon$ ненегативними, тобто якщо

$$
\begin{gathered}
c_{0} \geq(\mathbf{I}-\mathbf{A})^{-1}\left(d_{1}-s_{0}\right) \\
c_{t} \geq(\mathbf{I}-\mathbf{A})^{-1} d_{t}, \quad t=2, \ldots, T
\end{gathered}
$$

Очевидно, попит на продукцію не може бути задоволений, якщо початкова потужність i початковий запас недостатні для задоволення попиту першого періоду за рівнянням (10).

Найбільш важким випадком $є$ випадок, коли виконується умова (10), а умова (11) для деяких $t \geq$ 2 не виконується. У цьому випадку необхідно нарощувати виробничі потужності і створювати запаси продукції. Початкова фаза симплекс-методу використовується для перебування допустимого рішення системи або докази його відсутності. У випадку збільшення попиту в кожному періоді необхідно вводити декілька (за числом періодів) додаткових технологічних способів, використовуючи задані відношення збільшення попиту в якості коефіцієнтів при невідомих у цільовій функції.

Доведено [1], що двоетапні і багатоетапні задачі зводяться до задачі лінійного програмування 3 блочно-діагональною структурою виду

$$
\begin{aligned}
& \min \left\{Z=c_{1} x_{1}+c_{2} x_{2}+\ldots+c_{p} x_{p}\right\} \\
& A_{1} x_{1}+A_{2} x_{2}+\ldots+A_{p} x_{p}=b_{0} \\
& B_{1} x_{1} \quad=b_{1}
\end{aligned}
$$

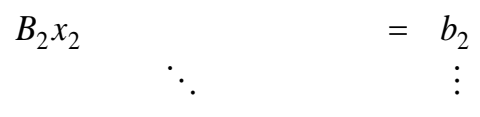

$$
\begin{aligned}
& B_{p} x_{p}=b_{p} \\
& x_{1} \geq 0, \quad x_{2} \geq 0, \quad \ldots \quad, \quad x_{p} \geq 0
\end{aligned}
$$

Макроекономічні динамічні задачі можуть бути представлені у виді (12). При обмеженому числі технологічних способів задача (12) може мати розмірність кілька тисяч. Задача (12) у цьому випадку має блочно-діагональну структуру і може бути розв'язана методом Данцига-Вульфа. Елементами матриць $B_{i}(i=1,2, \ldots, p) \in$ коефіцієнти витрати-випуску інгредієнтів, пов'язаних тільки 3 використанням технологічних способів $x_{i}$, в той час як $b_{0}$ задає обсяги інгредієнтів, що розподіляються між усіма способами. Матриця А містить коефіцієнти витрат випуску цих інгредієнтів. Матрицю обмежень задачі (12) можна записати у виді 


$$
\mathbf{A}=\left(\begin{array}{cccc}
A_{1} & A_{2} & \ldots & A_{p} \\
B_{1} & & & \\
& B_{2} & & \\
& & \ddots & \\
& & & B_{p}
\end{array}\right)
$$

Матриця будь-якої задачі лінійного програмування може бути приведена до такого виду $p=1 \mathrm{y}$ результаті відповідної розбивки обмежень на дві підмножини, оскільки стандартну задачу можна записати у виді:

$$
\begin{gathered}
\text { мінімізувати } \quad Z=C x \\
\left.\hat{A}_{1} x=b_{1} \text { ( } \text { (m }_{1} \text { обмежень }\right) \\
\hat{A}_{2} x=b_{2} \quad\left(m_{2} \text { обмежень }\right) \\
x>0
\end{gathered}
$$

Будь-який варіант розв'язання можна виразити як комбінацію крайніх точок області припустимих рішень

$$
x=\sum_{j} \lambda_{j} x^{j},
$$

де $\quad \sum_{j} \lambda_{j}=1, \quad \lambda_{j} \geq 0$.

Тоді задача (14)-(17) може бути сформульована так: необхідно вибрати з усіх розв'язань системи (16)-(17) таке, що задовольняє (15) і доставляє мінімум функції Z. Підставимо (18) у (17), отримаємо

$$
\sum_{j}\left(\hat{A}_{1} x^{j}\right) \lambda_{j}=b_{1} .
$$

Аналогічним образом отримаємо новий вираз для цільової функції

$$
Z=\sum_{j}\left(C x^{j}\right) \lambda_{j}
$$

Позначимо

$$
\begin{aligned}
& \hat{A}_{1} x^{j}=P_{j}, \\
& C x^{j}=f_{j} .
\end{aligned}
$$

враховуючи (18)-(19), приходимо до наступної задачі лінійного програмування: мінімізувати

$$
\sum_{j} f_{j} \lambda_{j}
$$

при обмеженнях

$$
\begin{gathered}
\sum_{j} P_{j} \lambda_{j}=b \\
\sum_{j} \lambda_{j}=1 \\
\lambda_{j} \geq 0
\end{gathered}
$$

Ця задача, еквівалентна початкової, називається координуючою [1]. Вона має тільки $m_{1}+1$ рядків у порівнянні $3\left(m_{1}+m_{2}\right)$ рядками початкової задачі і велику кількість стовпців. (Якщо $m_{2}-$ достатньо велике число, то число стовпців, рівне числу крайніх точок області припустимих рішень буде вимірюватися багатьма тисячами).

Розглянемо процедуру розв'язання. Для кожного $j$ обчислимо характеристичні різниці $[2,3]$ 


$$
\bar{f}_{j}=f_{j}-\pi\left(\begin{array}{c}
P_{j} \\
\vdots \\
1
\end{array}\right)
$$

Представимо $\pi$ у виді $\pi=\left(\pi_{1}, \pi_{0}\right)$, де $\pi_{1}-$ відповідає обмеженням (24), а скаляр $\pi_{0}$ - єдине обмеження (25). Використовуючи формули (21) та (22) можна записати

$$
\bar{f}_{j}=\left(C-\pi_{1} \hat{A}_{1}\right) x^{j}-\pi_{0}
$$

Для визначення змінної $\lambda_{s}$, яка вводиться в базис, необхідно знайти

$$
\min _{j} \bar{f}_{j}=f_{s}=\left(C-\pi_{1} \hat{A}_{1}\right) x^{s}-\pi_{0}
$$

Виконання операції (29) еквівалентно розв'язанню підзадачі виду:

$$
\begin{gathered}
\text { мінімізувати }\left(C-\pi_{1} \hat{A}_{1}\right) x \\
\text { при обмеженнях } \hat{A}_{2} x=b_{2}, x \geq 0
\end{gathered}
$$

Обчислення розв'язання $x_{s}$ цієї задачі дозволяє знайти стовпець, якому варто ввести в базис координуючої задачі

$$
P_{s}=\left(\begin{array}{c}
A_{1} x^{s} \\
\vdots \\
1
\end{array}\right)
$$

Відповідний коефіцієнт у цільовій функції дорівнює

$$
f_{s}=C x^{s} .
$$

Якщо число незалежних діагональних блоків більше одиниці, то початкова задача представляється у виді:

мінімізувати

$$
Z=c_{1} x_{1}+c_{2} x_{2}+\ldots+c_{p} x_{p}
$$

при обмеженнях

$$
\begin{array}{rrrr}
A_{1} x_{1}+A_{2} x_{2}+\ldots+A_{p} x_{p} & =b_{0} \\
B_{1} x_{1} & & & \\
& & b_{1} \\
& B_{2} x_{2} & & b_{2} \\
& & \ddots & \vdots \\
& & B_{p} x_{p} & =b_{p} \\
x_{1} \geq 0, \quad x_{2} \geq 0, \ldots, & x_{p} \geq 0, & p>1
\end{array}
$$

Для цього підзадача (30), (31) має вид:

$$
\text { мінімізувати } \sum_{i=1}^{p}\left(c_{i}-\pi_{1} A_{i}\right) x_{i}
$$

$$
\text { при обмеженнях } B_{i} x_{i}=b_{i}, x_{i} \geq 0,(i=1, \ldots, p) \text {. }
$$

Розв'язання задачі може бути отримане в результаті ізольованого розв'язку $P$ задач виду

$$
\begin{gathered}
\text { мінімізувати }\left(c_{i}-\pi_{1} A_{i}\right) x_{i} \\
\text { при обмеженнях } B_{i} x_{i}=b_{i}, x_{i} \geq 0 .
\end{gathered}
$$


Розглянемо дворівневий алгоритм розв'язання задачі (34)-(36), де на першому рівні необхідно розв’язати підзадачі (39)-(40), а на другому - координуючу задачу.

Нехай уже є припустимий базисний розв'язок задачі (23)-(26). Йому відповідає базисна матриця В та вектор оцінок обмежень $\left(\pi_{1}, \pi_{0}\right)$.

Крок 1. При використанні оцінок $\pi_{1}$ розв'язуються підзадачі (39)-(40) і знаходяться розв'язки $x_{i}\left(\pi_{1}\right)$ та оптимальні значення цільових функцій $z_{j}^{0}$.

Нехай $x\left(\pi_{1}\right)=\left(x_{1}\left(\pi_{1}\right), \ldots, x_{p}\left(\pi_{1}\right)\right)$.

Крок 2. Обчислюється $\min \bar{f}_{j}$ :

$$
\min \bar{f}_{j}=\sum_{i=1}^{p} z_{i}^{0}-\pi_{0}
$$

Якщо $\min \bar{f}_{j} \geq 0$ обчислення закінчуються, і визначається розв'язання задачі (34)-(36)

$$
x^{0}=\sum_{j б а_{3}} \lambda_{j} x^{j},
$$

де $\quad x_{j}-j$-я крайня точка області припустимих рішень, що відповідає базисної змінної $\lambda_{j}$.

Крок 3 . Якщо $\bar{f}_{j}<0$, формується стовпець

$$
\mathbf{P}=\left(\sum_{i} A_{i} x_{i}\left(\pi_{2}\right)\right) .
$$

Стовпець $\mathbf{P}$ збільшується на матрицю $\mathbf{B}^{-1}$ i $з$ використанням стандартної ведучої операції визначаються нові обернена матриця і вектор оцінок обмежень. Після виконання цих операцій варто повернутися до кроку 1 і перевірити обчислення [1].

\section{Висновки}

У результаті побудована модель багатогалузевої економічної (технологічної) системи та алгоритму знаходження оптимальних параметрів методом декомпозиції. При умові, що координуюча задача $\epsilon$ невиродженою, тоді на кожній ітерації значення цільової функції зменшується. Так як $є$ тільки кінцеве число можливих базисів і не один з них не використовується двічі, використання методу декомпозиції приведе до оптимального рішення за кінцеве число ітерацій.

\section{Список використаної літератури}

1. Сингх М. Системы: декомпозиция, оптимизация и управление / М. Сингх, А. Титли. М.: Машиностроение, 1986. 496 с.

2. Гамецкий А.Ф. Математическое моделирование макроэкономических процессов / А.Ф. Гамецкий, Д.И. Соломон Кишинеу: Еврика, 1997. 313 с.

3. Кротов В.Ф. Основы теории оптимального управления: Учеб. Пособие для эконом. вузов. / В.Ф. Кротов, Б.А. Лагоша, С.М. Лобанов и др. М.: Высшая школа, 1990. 430 с.

4. Димова Г.О. Методи і моделі упорядкування експериментальної інформації для ідентифікації $\mathrm{i}$ прогнозування стану безперервних процесів: монографія. / Ганна Олегівна Димова. Херсон: Видавництво ФОП Вишемирський В.С., 2020. 176 с.

5. Гельфонд А.О. Исчисление конечных разностей. / А.О. Гельфонд. М.: Гостехиздат, 1959. 400 с.

\section{References}

1. Singh M., Titley A. Sistemy: dekompozitsiya, optimizatsiya i upravleniye [Systems: decomposition, optimization and control] Moscow: Mashinostroyeniye, 1986. 496 p.

2. Gametskiy A.F., Solomon D.I. Matematicheskoye modelirovaniye makroekonomicheskikh protsessov [Mathematical modeling of macroeconomic processes] Chisinau: Evrika, 1997. 313 p.

3. V.F. Krotov, B.A. Lagosha, S.M. Lobanov et al. Osnovy teorii optimal'nogo upravleniya: Ucheb. Posobiye dlya ekonom. vuzov [Fundamentals of the theory of optimal control: Textbook. Benefit for the economy. universities] Moscow: Vysshaya shkola, 1990. $430 \mathrm{p}$.

4. Dymova H.O. Metody i modeli uporyadkuvannya eksperymental'noyi informatsiyi dlya identyfikatsiyi i prohnozuvannya stanu bezperervnykh protsesiv: monohrafiya [Methods and models for ordering experimental information for identifying and predicting the state of continuous processes] Kherson: Publishing house FOP Vyshemyrskyy V.S., 2020. 176 p.

5. Gelfond A.O. Ischisleniye konechnykh raznostey [Finite Difference Calculus] Moscow: Gostekhizdat, 1959. $400 \mathrm{p}$. 